\title{
Temporomandibular disorders, trismus and malignancy: development of a checklist to improve patient safety
}

IN BRIEF

- Outlines possible causes of trismus.

- Highlights that malignancy needs to be considered in the differential diagnosis of causes of trismus.

- Explains how the use of a checklist can improve patient safety.

Discusses the relevance of imaging in TMD.

\author{
H. P. Beddis, ${ }^{* 1}$ S. J. Davies, ${ }^{2,3}$ A. Budenberg, ${ }_{1}^{2}$ K. Horner ${ }^{2,3}$ \\ and M. N. Pemberton ${ }^{2,3}$
}

\section{VERIFIABLE CPD PAPER}

Trismus is a restriction in the ability to open the mouth. Trismus can occur following trauma, surgery, radiation therapy, infection, inflammatory diseases, temporomandibular disorders (TMD) or less commonly as a result of malignancy. Following two cases of delayed diagnosis of carcinoma presenting with features of TMD to a specialist clinic, a checklist was developed for completion in cases of trismus, to alert the clinician to suspicious features suggesting a possible nonTMD cause. The use of this checklist, together with an increased awareness, has improved early recognition of atypical features in patients presenting with trismus and has contributed to the early diagnosis of a further case of malignancy presenting to this clinic. This article discusses the presentation of malignancy with trismus, the relevance of imaging in these cases, and the implementation of a checklist to reduce the risk of future misdiagnosis.

\section{INTRODUCTION}

Trismus is a restriction in the ability to open the mouth. Eating, speech and other oral functions may be affected by trismus. The lower limit of normal maximum opening is $35 \mathrm{~mm}$ for females and $40 \mathrm{~mm}$ for males. A working group expanding upon the taxonomy of the widely-used 1992 research diagnostic criteria for temporomandibular disorders (TMD) defined trismus as a 'maximum assisted opening (passive stretch) including vertical incisal overlap of less than $40 \mathrm{~mm}^{1,2}$ However, many clinicians working in the field consider that this value is too high to be of clinical relevance; the authors would propose an upper limit of $30 \mathrm{~mm}$.

Many patients with trismus are likely to have a temporomandibular disorder (TMD). TMDs encompass a group of musculoskeletal and neuromuscular conditions that involve the temporomandibular joints (TMJs), the masticatory muscles and all associated tissues. $^{3}$ These conditions may arise from

Department of Restorative Dentistry, Leeds Dental Institute, Clarendon Way, Leeds, LS2 9LU; ${ }^{2}$ University Dental Hospital of Manchester, Central Manchester University Hospitals NHS Foundation Trust, Manchester Academic Health Science Centre, Higher Cambridge Street, Manchester, M15 6FH; ${ }^{3}$ School of Dentistry, University of Manchester

${ }^{*}$ Correspondence to: Hannah Beddis

Email: hannahbeddis@yahoo.co.uk

\section{Refereed Paper}

Accepted 19 June 2014

DOI: $10.1038 /$ sj.bdj.2014.862

${ }^{\circ}$ British Dental Journal 2014; 217: 351-355 disease, dysfunction or discomfort within the masticatory system.

Two common types of TMD that may result in trismus are myofascial pain (MP) and disc displacement without reduction (DD-WR). Trismus can have many possible causes, listed in Table 1.

It is rare for trismus to be the primary presenting sign of a malignancy, but it can happen. Consequently neoplasia should be considered in a patient presenting with trismus. There are reports in the literature of the misdiagnosis of malignancy in this way: for example, a temporal adenocarcinoma in a 62-year-old patient presenting with severe trismus and joint pain was initially misdiagnosed as a TMD. ${ }^{4}$ A number of other case reports describe trismus resulting from primary and metastatic carcinoma affecting the antrum, nasopharyngeal and parotid regions. ${ }^{5-7}$

In 2001, a patient initially attended the specialist TMD clinic at the University Dental Hospital of Manchester, where malignancy was the underlying cause of their symptoms, but where the symptoms were initially diagnosed as TMD (Patient A, Table 2). In 2009 a similar event occurred (Patient B, Table 3).

\section{DISCUSSION OF CASES}

Patients with symptoms and signs of TMD and trismus can present to dentists with a wide range of skills and experience. Consequently, TMD is managed by a wide variety of dentists including general

\section{Table 1 Possible causes of trismus}

Possible causes of trismus

TMD including myofascial pain, disc displacement without reduction

\section{Infection}

Forms of arthritis

Haematoma in medial pterygoid following ID block injection

Fibrosis (eg post-radiotherapy, scleroderma)

Trauma

Surgery

Malignancy

Ankylosis

Hyperplasia of the head of the condyle

Myositis ossificans

Tetanus

Tetany

CNS diseases (eg Parkinson's disease, multiple sclerosis)

Lack of patient co-operation

dental practitioners, dentists with a special interest, and hospital specialists from various disciplines including oral surgery, oral medicine, restorative dentistry and oral and maxillofacial surgery (OMFS). This heterogeneity of backgrounds may increase the potential for misdiagnosis unless the clinician's training has prepared him or her for all potential diagnoses. Recent guidance 


\section{Table 2 Patient A's journey}

\begin{tabular}{|c|c|c|c|c|}
\hline Patient journey & Presentation & $\begin{array}{l}\text { Working } \\
\text { diagnosis }\end{array}$ & Treatment at that stage & Comments \\
\hline \multicolumn{5}{|c|}{$\begin{array}{l}\text { Referral from general dental practitioner to department of oral medicine with persistence of symptoms diagnosed by the GMP as trigeminal neuralgia, } \\
\text { treatment with carbamazepine }\end{array}$} \\
\hline $\begin{array}{l}\text { Consultant in } \\
\text { oral medicine }\end{array}$ & $\begin{array}{l}\text { 'Lancinating pain', which had } \\
\text { initially been relieved by carbamaz- } \\
\text { epine (prescribed by the GMP) } \\
\text { Click in the left TMJ }\end{array}$ & $\begin{array}{l}\text { Trigeminal } \\
\text { neuralgia } \\
\text { Myofascial pain }\end{array}$ & $\begin{array}{l}\text { A soft bite guard was } \\
\text { fabricated and delivered } \\
\text { Referral to the TMD clinic }\end{array}$ & \\
\hline $\begin{array}{l}\text { Post-graduate } \\
\text { student in TMD }\end{array}$ & $\begin{array}{l}\text { Click had ceased } \\
\text { Tenderness to palpation of the } \\
\text { left TMJ, lateral pole and via an } \\
\text { intra-auricular approach } \\
\text { Click had ceased: no joint noises or } \\
\text { limitation of mouth opening } \\
\text { Discomfort at } 40 \mathrm{~mm} \text { opening }\end{array}$ & Myofascial pain & $\begin{array}{l}\text { Physiotherapy was } \\
\text { requested }\end{array}$ & $\begin{array}{l}\text { Physiotherapy was suspended following the } \\
\text { physiotherapist's report that despite the signs } \\
\text { and symptoms being 'strongly suggestive of } \\
\text { myofascial pain', an initial improvement had } \\
\text { not been maintained. }\end{array}$ \\
\hline TMD specialty dentist $A$ & & Myofascial pain & $\begin{array}{l}\text { Stabilisation (Michigan) } \\
\text { splint provided }\end{array}$ & $\begin{array}{l}\text { On review, the patient reported that the } \\
\text { symptoms had improved }\end{array}$ \\
\hline TMD specialty dentist B & $\begin{array}{l}\text { Deterioration in signs and } \\
\text { symptoms } \\
\text { Constant pain in the region } \\
\text { of the left ear and neck } \\
\text { Tenderness to palpation of all the } \\
\text { left-sided muscles of mastication } \\
\text { Trismus with maximum opening } \\
\text { of } 15 \mathrm{~mm} \text {. }\end{array}$ & $\begin{array}{l}\text { Disc displacement } \\
\text { without reduction }\end{array}$ & $\begin{array}{l}\text { A request was made for } \\
\text { further physiotherapy }\end{array}$ & $\begin{array}{l}\text { Physiotherapy was unfortunately not then } \\
\text { provided prior to the patient's subsequent } \\
\text { 4-monthly review, when the patient reported } \\
\text { no change in the condition. } \\
\text { The left-sided muscles remained tender to } \\
\text { palpation, and mouth opening was } 15 \mathrm{~mm} \text {. } \\
\text { The diagnosis of disc displacement without } \\
\text { reduction was maintained, and an arthro- } \\
\text { gram requested. }\end{array}$ \\
\hline $\begin{array}{l}\text { Consultant in maxillofa- } \\
\text { cial radiology }\end{array}$ & $\begin{array}{l}\text { Arthrogram was carried out and } \\
\text { reported upon }\end{array}$ & & & $\begin{array}{l}\text { The radiography report stated that 'the disc } \\
\text { was mildly anterior in position in the closed } \\
\text { position... that the disc was not translating } \\
\text { normally over the condyle. Almost complete } \\
\text { reduction eventually achieved on anterior } \\
\text { translator movement.' }\end{array}$ \\
\hline $\begin{array}{l}\text { Lead clinician, TMD } \\
\text { clinic and consultant in } \\
\text { oral and maxillofacial } \\
\text { surgery A }\end{array}$ & & $\begin{array}{l}\text { Disc displacement } \\
\text { without reduction }\end{array}$ & Arthrocentesis carried out & $\begin{array}{l}\text { The patient was from then on seen within the } \\
\text { Oral and Maxillofacial Surgery Department. } \\
\text { Following arthrocentesis, no improvement } \\
\text { was noted, and bilateral eminectomy advised. } \\
\text { MR imaging was requested }\end{array}$ \\
\hline $\begin{array}{l}\text { Specialist registrar } \\
\text { in OMFS and consultant } \\
\text { in OMFS B }\end{array}$ & $\begin{array}{l}\text { Mouth opening was } 10 \mathrm{~mm} \\
\text { Constant left sided pain } \\
\text { Right-sided pain } \\
\text { Nasal congestion, discharge } \\
\text { and epistaxis }\end{array}$ & & & $\begin{array}{l}\text { MRI revealed an extensive tumour filling the } \\
\text { left antrum, with involvement of the hard } \\
\text { palate, lateral and posterior walls of sinus, } \\
\text { inferior medial wall of the orbit, ethmoid } \\
\text { sinus, pharynx and infratemporal fossa. This } \\
\text { tumour was subsequently diagnosed as an } \\
\text { adenoid cystic carcinoma. }\end{array}$ \\
\hline
\end{tabular}

\section{Table 3 Patient B's journey}

\begin{tabular}{|c|c|c|c|c|}
\hline Patient journey & Presentation & Working diagnosis & Treatment at that stage & Comments \\
\hline $\begin{array}{l}\text { TMD specialty } \\
\text { dentist }\end{array}$ & $\begin{array}{l}\text { Right-sided difficulty in opening the mouth } \\
\text { History of neuralgia-type pain in the right ear } \\
\text { Symptoms had been present for 2-3 months } \\
\text { No joint noises } \\
\text { Tenderness of the right lateral pterygoid } \\
\text { muscle to resisted movement test } \\
\text { Maximum opening was } 12 \mathrm{~mm}\end{array}$ & $\begin{array}{l}\text { Disc displacement } \\
\text { without reduction } \\
\text { secondary to spasm } \\
\text { of the right lateral } \\
\text { pterygoid muscle }\end{array}$ & $\begin{array}{l}\text { Home physiotherapy } \\
\text { exercises }\end{array}$ & \\
\hline $\begin{array}{l}\text { TMD specialty } \\
\text { dentist }\end{array}$ & $\begin{array}{l}\text { No improvements in symptoms } \\
\text { New non-tender swelling under the right } \\
\text { body of mandible } \\
\text { New development of paraesthesia of the } \\
\text { right side of tongue } \\
\text { Pain in the right mandible }\end{array}$ & & $\begin{array}{l}\text { Patient given a same- } \\
\text { day appointment in } \\
\text { the Department of Oral } \\
\text { Medicine }\end{array}$ & \\
\hline $\begin{array}{l}\text { Consultant in } \\
\text { oral medicine }\end{array}$ & $\begin{array}{l}\text { Palpable right-sided lymph nodes at levels } \\
\text { I and II } \\
\text { Suspicious mucosal lesion adjacent to the } \\
\text { lower right molars }\end{array}$ & & $\begin{array}{l}\text { OPG requested. } \\
\text { Same-day onward } \\
\text { referral to head and neck } \\
\text { cancer surgeon, OMFS. }\end{array}$ & $\begin{array}{l}\text { Panoramic radiograph revealed } \\
\text { erosion of the alveolar aspect of the } \\
\text { mandible plus area of radiolucency in } \\
\text { the right ramus } \\
\text { Subsequent EUA and biopsy } \\
\text { confirmed the clinical suspicion of } \\
\text { oral squamous cell carcinoma }\end{array}$ \\
\hline
\end{tabular}


has been published for the assessment, diagnosis and management of TMD within primary care, which forms the appropriate setting for the management of many TMD patients. ${ }^{8}$

The specialist TMD clinic in Manchester is long established but nevertheless is staffed by a variety of different grades of staff. All clinicians need to be aware that the diagnosis of the condition causing the patient's trismus may fall outside their experience and expertise, and must remain unbiased and open-minded to possible alternative diagnoses. ${ }^{9}$

Patient cases such as these described here must be used to provide learning experiences rather than the apportioning of blame. Patient A's journey within the dental hospital involved a number of senior clinicians in multiple specialties. This point is not made to demonstrate how many clinicians may have misdiagnosed the pathology, but rather that these clinicians, with their range of areas of expertise and backgrounds, all supported the diagnosis of TMD made at that time. This diagnosis was, at that time, a reasonable one, and the patient was treated appropriately to that diagnosis. Very sadly, however, a neoplasia was the underlying cause of, or developed subsequent to this patient's TMD. Trismus was not initially present, but developed early on in the evolution of symptoms. This case represents an unusual presentation of a maxillary tumour. Until very late on, there were no 'classic' symptoms such as: nasal stuffiness, discharge or epistaxis; fullness or tenderness over the malar regions; paraesthesia or anaesthesia.

Patient B had a shorter journey, but the correct diagnosis was delayed because of tenderness of masticatory muscles guiding the dentist to a TMD diagnosis rather than underlying malignancy. Following this second case, a root cause analysis of the patient's journey was undertaken and TMD clinicians on the clinic discussed how they might reduce the risk of such misdiagnosis in the future. The discussion centred on the use of imaging and a checklist.

\section{IMAGING FOR TMD-TYPE SYMPTOMS}

The appropriateness of imaging in TMD patients is the subject of some debate.

The 1992 research diagnostic criteria for TMD state that 'imaging may help substantiate a clinical impression but lacks the ability to discriminate between symptomatic and asymptomatic patients.' ${ }^{1}$ As such, the diagnosis and treatment plan are made on a clinical basis; radiographs will not change the outcome and therefore are of little value. Other authors have reiterated the clinical nature of the diagnostic and treatment planning process in TMD and recommended a reduction in the use of imaging, deeming it of uncertain benefit to the patient, potentially costly and carrying the risk of stochastic effects associated with radiographic exposure. ${ }^{10}$ These views are reiterated in national and European guideline documents. ${ }^{11,12}$

However, as shown here, patients may occasionally present with symptoms initially considered to be TMD but subsequently found to be due to other causes. This raises the question as to when radiography should be undertaken. Using X-ray imaging requires adherence to the principle of justification, which requires that the benefits to the patient should outweigh the risk and this is incorporated into European Directive and UK law. ${ }^{11,13}$ The individual radiation dose is, however, small and it might be argued that it is worth imaging all or most patients with TMD so that the extremely rare case of malignancy is not overlooked. This approach, of course, fails to take into account the statistical chance of X-ray exposure causing a cancer, but also the basics of health economics. To 'screen' patients with TMD by panoramic radiography would have an associated 'opportunity cost', that is, cost health services money that would not be available for something else. ${ }^{14}$ There is evidence that when panoramic radiography is used routinely to screen new adult patients that the benefit is very small compared with selected intraoral radiographs. ${ }^{15}$ To advocate screening of TMD patients has no evidence to support it and is not recommended. ${ }^{16}$

Another aspect to consider is the diagnostic accuracy efficacy of panoramic radiography in the specific context of malignancy.

Some authors have reported limited sensitivity of panoramic radiography in the detection of bony destruction in malignancy. Compared to computed tomography (CT) imaging, panoramic radiographs have shown limited ability to demonstrate the extent of lesions or soft tissue involvement. ${ }^{17,18}$ Furthermore, previously reported examples of malignancy presenting as a TMD had initial panoramic radiography, which did not demonstrate abnormality. ${ }^{4}$

A few studies have looked at this issue. A 1996 study compared plain panoramic radiograph and CT images of 20 patients with antral malignancy. ${ }^{19}$ Panoramic radiographs were found to detect bony destruction in 90\% of cases confirmed on CT imaging, but were deemed poorly able to determine the extent of the malignancy. Soft tissue masses were demonstrated in 95\% of CT images, but only $35 \%$ of panoramic radiographs. ${ }^{19}$ Kushraj reported an 'acceptable' degree of sensitivity (correct identification of a positive result), with six out of eight panoramic radiographs demonstrating bony invasion. ${ }^{20}$ Patient B did have a pathology that was evident on plain radiography, so it could be argued that had such an investigation been performed in the first instance, it may have allowed earlier diagnosis. Following review of these cases, we now more actively consider whether to undertake a radiograph in each of our patients presenting with symptoms of TMD according to the balance of probability of TMD being the underlying cause.

As discussed above, however, plain radiographs are not a reliable investigation for malignancy mimicking TMD symptoms and where malignancy is suspected, more advanced imaging is warranted. ${ }^{21}$ Advanced imaging in the form of CT and magnetic resonance imaging (MRI) are now widely available and are the appropriate imaging modalities in cases of suspected malignancy. MRI has the advantage that no ionising radiation is involved and hence adverse effects are negligible. It should be noted that cone beam $\mathrm{CT}$, which is increasingly available in dental practice, should not be used when malignancy is suspected as it is effectively limited to imaging hard tissues due to very limited soft tissue contrast. ${ }^{22}$

\section{DEVELOPMENT OF A CHECKLIST FOR PATIENTS REFERRED WITH TMD}

In 2007, the World Health Organisation (WHO) developed a checklist to improve patient safety in the operating theatre. ${ }^{23}$ This checklist requires involvement of surgical, anaesthetic and nursing staff, who must confirm aloud a number of key aspects of care for example, patient identification, known allergies, planned procedure, presence of signed consent form and surgical site marking. These confirmations are made before specific aspects of operative care: before induction of anaesthesia, before commencement of the procedure and before leaving the operating theatre. The implementation of this checklist has successfully reduced complications and patient mortality. ${ }^{24}$

Checklists could therefore be of value in other aspects of medical and dental care. A checklist can serve as an aide-memoire to ensure that essential aspects of care are not omitted. Even if some aspects of care are deemed 'routine', a checklist will help aid consistency.

The cases detailed above had severe consequences for the patients involved. A reduction in delayed or misdiagnosis of malignancy is obviously of great importance, 
and this potential cause must therefore be considered in all patients presenting with a reduction in mouth opening.

To help reduce the risk of delayed diagnosis of malignancy in cases of trismus, a checklist and flowchart were devised for use within the TMD Clinic in 2011. The first step on examination is to measure and record mouth opening for all patients. If this is less than $30 \mathrm{~mm}$, the checklist (Table 4) must be completed. This checklist includes associated factors that act as 'red flags' to alert the clinician to the possibility of an underlying alternative pathology to TMD including malignancy. Any 'yes' answers in the checklist necessitates a referral to the joint clinic held fortnightly within the TMD clinic, staffed by a senior restorative dentistry and OMFS clinician, for further assessment and imaging as deemed necessary. If malignancy is strongly suspected at the initial visit, then immediate referral to an OMFS consultant with an interest in head and neck cancer can be undertaken directly, rather than referral to the joint clinic.

Initial audit of use of the checklist in 2011 within the TMD clinic found that following the introduction of the checklist, mouth opening was being recorded in 90\% of case notes and the checklist was being completed correctly in 71\% of cases where trismus had been identified. The results were discussed among the clinicians and any misunderstandings or barrier to the use of the checklist explored and its use clarified. Re-audit of the checklist in 2012 showed an increase in the recording of mouth opening to $96 \%$ of case notes and $100 \%$ completion of the checklist where trismus had been identified. It is planned that this audit on the use of the checklist will now be repeated on a yearly basis to monitor its use and to act as a focus for discussion as changes in clinic staff occur.

In both cases reported above, completion of the flowchart and trismus checklist would have led to earlier onward referral. Patient A would have scored 'yes' answers in 'opening less than $15 \mathrm{~mm}$,' 'progressively worsening trismus' and 'pain of non-myofascial origin.'
Table 4 Trismus checklist: for completion in patients with reduced mouth opening

\begin{tabular}{l|l|l} 
& Yes & No \\
\hline Opening less than $15 \mathrm{~mm}$ & & \\
\hline Progressively worsening trismus & & \\
\hline Absence of history of clicking & & \\
\hline Pain of non-myofascial origin (neuralgia etc) & & \\
\hline Swollen lymph glands & & \\
\hline Suspicious intra-oral soft tissue lesion & & \\
\hline
\end{tabular}

If any of the answers are yes, consider radiograph and arrange review with senior clinician

Patient B would have scored 'yes' on the checklist to 'opening less than $15 \mathrm{~mm}$,' 'absence of history of clicking,' and 'pain of non-myofascial origin.'

In 2013 another patient presented on referral from his general dental practitioner with features of TMD but where the underlying pathology was malignancy (Patient C, Table 5). On completing the checklist the TMD speciality dentist realised that the features were atypical and was able to access advice from a senior restorative and an OMFS colleague that day; ultimately leading to a speedy diagnosis of an oral squamous cell carcinoma. 'Yes' answers on the checklist were given to 'opening less than $15 \mathrm{~mm}$,' 'progressively worsening trismus' and 'suspicious intraoral soft tissue lesion.' Both the practical use of the checklist and the culture change engendered in the TMD clinicians by reflection on previous misdiagnosis and engagement with the production of a checklist has contributed to this improvement in early recognition of atypical features and early diagnosis of malignancy.

This paper has focused on the possibility that malignancy presenting with trismus may be misdiagnosed. It should be remembered that malignancy might also mimic other symptoms of TMD, for example, persistent pain, without necessarily causing trismus. Clinicians managing TMD should always keep these rare but important possible differential diagnoses in mind.

\section{CONCLUSION}

Malignancy must be considered in the differential diagnoses in cases of trismus. It is therefore essential that a thorough and consistent thought process and care pathway be followed, in order to reduce the risk of delayed or misdiagnosis. This can be aided by the use of a checklist.

In the context of supposed TMD, a key role of the various clinicians who contribute to the TMD service is to diagnose when a TMD is or is not present, or where there are suspicious or atypical factors. The clinician must have an awareness of when to refer onwards. The use of a checklist such as the one described assists in this awareness and in our clinic has contributed to a subsequent early diagnosis of a case of malignancy presenting as trismus.

This trismus checklist could be used by general dental practitioners with an interest in TMD as well as within general dental practice more widely. The role of the general dental practitioner is not to diagnose malignancy but to determine where the presenting symptoms and signs mean there is a need for onward referral and the urgency of referral needed. This checklist could assist in the assessment of referral in patients presenting with trismus.

\footnotetext{
Dworkin S F. Research diagnostic criteria for temporomandibular disorders: current status and future relevance. J Oral Rehabil 2010; 37: 734-743.

2. Peck C C, Goulet J P, Lobbezoo F et al. Expanding the taxonomy of the diagnostic criteria for temporomandibular disorders. J Oral Rehabil 2014;
}

Table 5 Patient C's journey

\begin{tabular}{|c|c|c|c|}
\hline Patient journey & Presentation & Treatment at that stage & Comments \\
\hline \multicolumn{4}{|c|}{ Referral from GDP to TMD clinic due to trismus } \\
\hline $\begin{array}{l}\text { TMD specialty } \\
\text { dentist }\end{array}$ & $\begin{array}{l}\text { Worsening limitation of opening, persisting despite } \\
\text { three courses of antibiotics from the GDP } \\
10 \mathrm{~mm} \text { inter-incisal opening } \\
\text { Pain on palpation over right masseteric region } \\
\text { Suspicious lesion and thickening of buccal mucosa } \\
\text { identified. }\end{array}$ & $\begin{array}{l}\text { Trismus checklist used, and resultant } \\
\text { high level of suspicion identified. } \\
\text { Discussion with OMFS SpR for opinion } \\
\text { Same-day onward referral to head and } \\
\text { neck cancer surgeon, OMFS. } \\
\text { OPG requested }\end{array}$ & $\begin{array}{l}\text { Imaging revealed erosion of the right } \\
\text { body of mandible }\end{array}$ \\
\hline Consultant in OMFS & & Biopsy of lesion in buccal mucosa & $\begin{array}{l}\text { Biopsy revealed moderately } \\
\text { differentiated squamous cell carcinoma }\end{array}$ \\
\hline
\end{tabular}


41: 2-23

3. American Association for Dental Research. Policy statements. AADR, 1982. Online information available at http://www.aadronline.org/i4a/pages/ index.cfm?pageid=3465 (accessed June 2014).

4. Honda K, Natsumi Y, Sakurai K, Ishikura R, Urade M. Mucinous adenocarcinoma of the temporal region initially diagnosed as temporomandibular disorders: a case report. J Oral Pathol Med 2006; 35: 582-585.

5. Ozyar E, Cengiz M, Gurkaynak M, Atahan I L. Trismus as a presenting symptom in nasopharyngeal carcinoma. Radiother Oncol 2005; 77: 73-76.

6. Patrocinio L G, Patrocinio T G, Pacheco L F, Patrocinio J A. Trismus as the first manifestation of cholangiocarcinoma. Med Oral Patol Oral Cir Bucal 2008; 13: E573-E575.

7. Dimitrakopoulos I, Ntomouchtsis A, lordanidis F. Infratemporal fossa metastasis from carcinoma of the uterine cervix. Oral Maxillofac Surg 2011; 15: 121-125.

8. Temporomandibular disorders (TMDs): an update and management guidance for primary care from the UK Specialist Interest Group in Orofacial Pain and TMDs (USOT). London: Royal College of Surgeons, Faculty of Dental Surgery, 2013. Online guidelines available at http://www.rcseng.ac.uk/fds/publications-clinicalguidelines/clinical guidelines (accessed June 2014).

9. Cain D M, Detsky A S. Everyone's a little bit biased (even physicians). JAMA 2008; 299: 2893-2895.

10. Petersson A. What you can and cannot see in TMJ imaging-an overview related to the RDC/TMD diagnostic system. J Oral Rehabil 2010; 37: 771-778.

11. Council directive 97/43/Euratom of 30 June 1997 on health protection of individuals against the dangers of ionizing radiation in relation to medical exposure. European Communities, 1997. Online directive available at http://ec.europa.eu/energy/nuclear/ radioprotection/doc/legislation/9743_en.pdf (accessed June 2014).

12. European Commission. Radiation protection 136 European guidelines on radiation protection in dental radiology. European Commission 2004. Online guidelines available at http://ec.europa. eu/energy/nuclear/radioprotection/publication/ doc/136_en.pdf. (accessed June 2014).

13. The ionising radiation (medical exposure) regulations 2000. Online regulations available at $h t t p: / / w w w$. legislation.gov.uk/uksi/2000/1059/contents/made (accessed June 2014).

14. Drummond M F, Sculpher M J, Torrance G W et al. Methods for the economic evaluation of health care programmes. 3rd ed. Oxford: Oxford University Press, 2005.

15. Rushton M N, Rushton VE. A study to determine the added value of 740 screening panoramic radiographs compared to intraoral radiography in the management of adult ( $>18$ years) dentate patients in a primary care setting. J Dent 2012; 40: 661-669.

16. Horner K, Eaton K A. Selection criteria for dental radiography. 3rd ed. London: Faculty of General Dental Practice (UK), 2013.

17. Momin M A, Okochi K, Watanabe H et al. Diagnostic accuracy of cone-beam CT in the assessment of mandibular invasion of lower gingival carcinoma: comparison with conventional panoramic radiography. Eur J Radio/ 2009; 72: 75-81.

18. Pereira A C, Cavalcanti M G, Tossato PS, Guida
FJ, Duaik M C, Kuroishi M. Analysis of epidermoid carcinomas using panoramic radiography and computerized tomography. Pesqui Odontol Bras 2001; 15: 320-326.

19. Epstein J B, Waisglass M, Bhimji S, Le N, StevensonMoore P. A comparison of computed tomography and panoramic radiography in assessing malignancy of the maxillary antrum. Eur J Cancer B Oral Oncol 1996; 32B: 191-201.

20. Kushraj T, Chatra L, Shenai P, Rao P K. Bone invasion in oral cancer patients: a comparison between Orthopantamograph, conventional computed tomography, and single positron emission computed tomography. J Cancer Res Ther 2011; 7: 438-441.

21. Royal College of Radiologists. iRefer guidelines: Making the best use of clinical radiology-Version 7.0.2. 2012. Online guidelines available at http:// www.irefer.org.uk/index.php/about-irefer (accessed June 2014).

22. European Commission. Radiation protection 172. Cone beam CT for dental and maxillofacial radiology. Luxembourg: Office for Official Publications of the European Communities, 2012. Online guidelines available at http://ec.europa.eu/energy/nuclear/ radiation_protection/doc/publication/172.pdf (accessed June 2014).

23. World Health Organization. Patient safety checklist. WHO, 2007. Online information available at http:// www.who.int/patientsafety/safesurgery/checklist/en/ (accessed June 2014).

24. Haynes A B, Weiser T G, Berry W R et al. A surgical safety checklist to reduce morbidity and mortality in a global population. N Engl J Med 2009; 360: 491-499 